\title{
Induction of D-Amino-acid Oxidase by D-Alanine in Rhodotorula gracilis Grown in Defined Medium
}

\author{
By MIRELLA PILONE SIMONETTA, * ROBERTO VERGA, \\ ANTONELLA FRETTA AND GIORGIO M. HANOZET \\ Department of General Physiology and Biochemistry, University of Milan, via Celoria 26, \\ 20133 Milano, Italy
}

(Received 8 August 1988; revised 29 October 1988; accepted 7 November 1988)

\begin{abstract}
The obligate aerobe yeast Rhodotorula gracilis was grown in batch culture on a chemically defined, $\mathrm{pH}$-controlled medium containing glucose or D-alanine as carbon sources, ammonium or D-alanine as nitrogen sources, and D-alanine as a sole carbon and nitrogen source. Under these conditions, D-alanine induced the synthesis of D-amino-acid oxidase (EC 1.4.3.3) to an extent depending on the nutrients, the highest specific activity of the enzyme [up to $0.6 \mathrm{U}$ (mg protein $)^{-1}$ ] being detected when both $\mathrm{D}$-alanine and glucose were present in the growth medium. In contrast, enzyme activity was negligible when both ammonium and glucose were present in the growth medium, even in the presence of $\mathrm{D}$-alanine. The racemic mixture DL-alanine was also utilized as a source of both carbon and nitrogen for the growth of $R$. gracilis, but the enzyme activity appeared only after the depletion of L-alanine from the medium. Data on transmembrane transport of $D$-alanine in the presence of different nutrients clearly indicated that the L-isomer prevented induction by D-alanine through inhibition of the transport of the D-amino acid into cells. However, such an effect was not exerted by ammonium, indicating that this compound probably acts at the level of enzyme synthesis.
\end{abstract}

\section{INTRODUCTION}

D-Amino-acid oxidase (DAAO) [D-amino-acid:oxygen oxidoreductase (deaminating), EC 1.4.3.3] is a flavoprotein that catalyses the oxidation of $\mathrm{D}$-amino acids to the corresponding 2-oxoacids and ammonia with the concurrent reduction of molecular oxygen to hydrogen peroxide. The presence of DAAO has been reported in many organisms, but its metabolic function is yet unclear, especially in eukaryotes (Hamilton, 1985). Despite this ubiquitous distribution, for many years the only DAAO available in homogeneous form has been the enzyme from pig kidney (Brigth \& Porter, 1975).

We have previously shown that de novo synthesis of DAAO can be selectively induced in the oleaginous yeast Rhodotorula gracilis by addition of D- or DL-amino acids to an organic growth medium, the inductive effect being strictly dependent on the presence of the D-isomer (Pilone Simonetta et al., 1982). The appearance of enzyme activity was related to the onset of stationary phase, and maximal induction was obtained with D- or DL-alanine. Induction of DAAO by D-amino acids has also been described in other micro-organisms, namely Neurospora crassa (Sikora \& Marzluf, 1982), Trigonopsis variabilis (Kubicek-Pranz \& Röhr, 1985a) and Candida utilis (Zwart et al., 1983) - which utilizes D-alanine as a sole carbon and nitrogen source for its growth. The enzyme was partially purified from $C$. utilis, but was unstable upon further purification. DAAO was also purified from $T$. variabilis almost to homogeneity, but the final preparation was highly unstable (Kubicek-Pranz \& Röhr, 1985b). 
Recently we purified DAAO to homogeneity from $R$. gracilis, obtaining a final stable preparation with a specific activity of about $60 \mathrm{U}$ (mg protein) ${ }^{-1}$ (Pilone Simonetta et al., $1987 a, b)$. We also provided evidence that DAAO from this yeast is an FAD-containing enzyme with properties typical of the dehydrogenase/oxidase class of flavoproteins, following the classification of Massey \& Hemmerich (1980). However, the low content of DAAO in $R$. gracilis cells grown under the conditions previously reported resulted in a low yield and a low reproducibility during enzyme purification. In the present paper, we report an investigation into the regulation by nutrients of DAAO synthesis in $R$. gracilis, which led to a considerably improved DAAO production and to a 15 -fold increase of enzyme specific activity.

\section{METHODS}

Growt conditions and preparation of cell extracts. $R$. gracilis (synonym Rhodosporidium toruloides, ATCC 26217) was grown aerobically in the dark with shaking at $30^{\circ} \mathrm{C}$ in a liquid basal medium containing nitrogen and carbon sources as indicated in the tables and figures. The basal medium contained $8.6 \mathrm{~mm}-\mathrm{NaCl}, 4 \mathrm{~mm}-\mathrm{MgSO}_{4}$, $5.7 \mathrm{mM}_{2}-\mathrm{K}_{2} \mathrm{HPO}_{4}, \quad 2.3 \mathrm{mM}^{-\mathrm{CaCl}_{2}}, \quad 7 \mu \mathrm{M}-\mathrm{ZnSO}_{4}, \quad 16.5 \mu \mathrm{M}-\mathrm{FeNa}-$ EDTA, $15 \mu \mathrm{M}$-thiamine-HCl, $10 \mu \mathrm{M}$-calcium pantothenate and $100 \mathrm{~mm}-\mathrm{MES} / \mathrm{KOH} \mathrm{pH} 5 \cdot 6$. The sterilized medium ( $200 \mathrm{ml}$ in a $750 \mathrm{ml}$ flask) was inoculated with $0.5 \mathrm{ml}$ of a cell suspension $\left(\mathrm{OD}_{660}=10\right)$ from a slant. Growth was followed by optical density measurements at $660 \mathrm{~nm}$; the number of cells was also estimated by microscopic observation in a counting chamber. The correlation between the two measurements was determined. The cells were harvested by centrifugation or by filtration on a cellulose membrane. Cell extracts were prepared according to Funayama et al. (1980) in $100 \mathrm{~mm}$-potassium phosphate buffer $\mathrm{pH} 7 \cdot 5$, containing 2 mM-EDTA, $5 \mathrm{~mm}-\beta$-mercaptoethanol and $0.3 \%$ cetylpyridinium bromide. The resultant homogenate was centrifuged at $100000 \mathrm{~g}$ for $30 \mathrm{~min}$ and the supernatant was used directly in the assay.

Induction experiments. Cells grown to different growth phases in basal medium containing 50 mm-glucose and $15 \mathrm{~mm}$-ammonium sulphate were harvested by filtration, washed with cold distilled water and suspended to a final concentration of $4 \mathrm{~g}$ wet weight $100 \mathrm{ml}^{-1}\left(\mathrm{OD}_{660}=10\right)$ in basal medium containing $50 \mathrm{mM}$-glucose and $30 \mathrm{~mm}$-D-alanine. The cells were then incubated at $30^{\circ} \mathrm{C}$ on a shaker and the appearance of DAAO specific activity was measured for up to $5 \mathrm{~h}$ of incubation.

Enzyme assay and analyses. DAAO activity was assayed polarographically at $37^{\circ} \mathrm{C}$ in $100 \mathrm{~mm}$-sodium pyrophosphate buffer, $\mathrm{pH} 8 \cdot 5$, containing $28 \mathrm{~mm}$-D-alanine (or $56 \mathrm{mM}$-DL-alanine). Addition of exogenous FAD to the assay medium did not increase enzyme activity. One unit of activity (U) corresponds to the uptake of $1 \mu \mathrm{mol}$ oxygen $\min ^{-1}$. Protein was measured by a biuret method (Burkhard Kresze, 1983). The D-alanine and L-alanine concentrations in the growth media were determined by the method of Grassl \& Supp $(1983 a, b)$.

Electrophoretic methods. Electrophoretic analyses of $100000 \mathrm{~g}$ supernatants were performed according to Davis (1964). DAAO activity staining was carried out as described by Pilone Simonetta et al. (1987a).

Uptake experiments. The uptake of D-alanine by yeast cells was measured by a rapid filtration technique at room temperature. Cells from cultures in different growth phases were harvested by filtration, washed with cold distilled water and suspended to a final concentration of $4 \mathrm{~g}$ wet weight $100 \mathrm{ml}^{-1}\left(\mathrm{OD}_{660}=10\right)$ in basal medium containing $50 \mathrm{~mm}$-glucose. Following a preliminary incubation at $30^{\circ} \mathrm{C}$ for $15 \mathrm{~min}$ with shaking, a $100 \mu \mathrm{l}$ sample was withdrawn and mixed with $100 \mu \mathrm{l}$ of basal medium, $50 \mathrm{~mm}$-glucose and $2 \mathrm{~mm}-\mathrm{D}-\left[{ }^{14} \mathrm{C}\right]$ alanine $\left(10 \mu \mathrm{Ci} \mathrm{ml}{ }^{-1}\right.$; $370 \mathrm{kBq} \mathrm{ml}^{-1}$ ). At selected times $50 \mu \mathrm{l}$ samples were withdrawn, diluted with $1.5 \mathrm{ml}$ of chilled basal medium containing $50 \mathrm{~mm}$-glucose and then immediately filtered through a cellulose nitrate filter $(0.65 \mu \mathrm{m}$ pore size $)$. The filter was washed twice with $5 \mathrm{ml}$ of the same solution, put into a vial, and counted in a liquid scintillation spectrometer. Uptake was expressed as $\mathrm{nmol} \mathrm{min}^{-1}(\mathrm{mg} \text { whole-cell protein })^{-1}$. D- $\left[{ }^{14} \mathrm{C}\right]$ Glucose uptake was measured following the same procedure, except that the cells were suspended in basal medium containing $15 \mathrm{~mm}$-ammonium sulphate.

Chemicals. D-Alanine was purchased from Fluka, DL-alanine and MES from Merck, and D- $\left[{ }^{14} \mathrm{C}\right]$ alanine and $\mathrm{D}-\left[{ }^{14} \mathrm{C}\right]$ glucose from Amersham. All other chemicals were of the highest available grade.

\section{RESULTS AND DISCUSSION}

We have used a chemically defined growth medium to elucidate the effect of nutrients on DAAO synthesis. Since, in the presence of alanine, the yeast culture exhibited a large upward $\mathrm{pH}$ shift during growth, the $\mathrm{pH}$ of the medium was kept constant by buffering. Our preliminary data showed that the best experimental conditions for growth of $R$. gracilis were pH 5.6 in a medium supplied with MES.

Cells were then grown in batch culture in a synthetic medium containing glucose or D-alanine as carbon sources, ammonium or D-alanine as nitrogen sources, and D-alanine as a sole carbon 


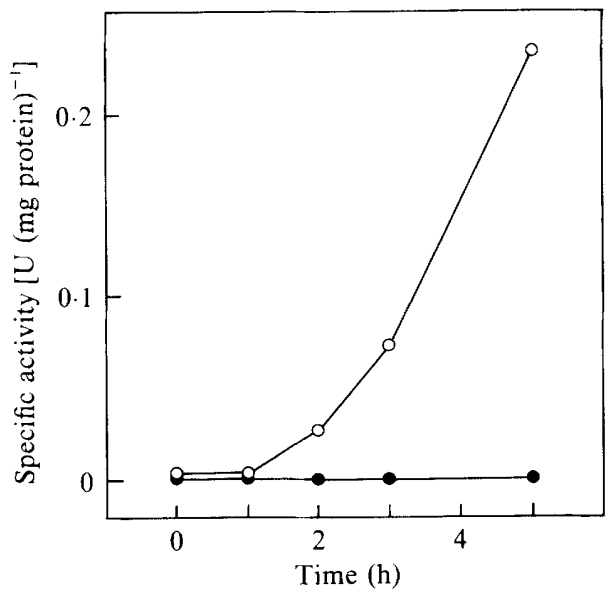

Fig. 1. Effect of cycloheximide on the DAAO activity induced by D-alanine. Cells were grown for $16 \mathrm{~h}$ in basal medium containing $50 \mathrm{~mm}$-glucose plus $15 \mathrm{mM}$-ammonium sulphate, harvested, washed and suspended in basal medium containing $50 \mathrm{mM}$-glucose plus $30 \mathrm{~mm}$-D-alanine with $(\bullet)$ or without $(O)$ $100 \mu \mathrm{M}$-cycloheximide. DAAO specific activity was measured at the times specified after the addition of D-alanine.

Table 1. Effect of glucose, ammonium and D-alanine on DAAO specific activity and on growth

Cells were grown on basal medium with the compounds indicated by.$+ \mu$, Specific growth rate.

$\begin{array}{cccccc}\begin{array}{c}\text { Glucose } \\ (50 \mathrm{mM})\end{array} & \begin{array}{c}\left.\mathrm{NH}_{4}\right)_{2} \mathrm{SO}_{4} \\ (15 \mathrm{mM})\end{array} & \begin{array}{c}\text { D-Ala } \\ (\mathrm{mM})\end{array} & \begin{array}{c}\mu \\ \left(\mathrm{h}^{-1}\right)\end{array} & \overbrace{\text { Exp. phase }}^{\begin{array}{c}\text { DAAO specific activity } \\ {\left[\mathrm{U}(\mathrm{mg} \text { protein })^{-1}\right]}\end{array}} & \text { Stat. phase } \\ + & + & 0 & 0.231 & 0.005 & 0.005 \\ + & - & 30 & 0.191 & 0.548 & 0.572 \\ + & + & 30 & 0.198 & 0.019 & 0.071 \\ + & - & 100 & 0.063 & 0.130 & 0.170 \\ - & + & 100 & 0.057 & 0.140 & 0.170\end{array}$

and nitrogen source (Table 1). The results show that $R$. gracilis was able to grow in a synthetic medium containing $\mathrm{D}$-alanine as the only carbon and nitrogen source, although the specific growth rate was low. DAAO was virtually absent when no D-alanine was supplied, while the addition of D-alanine to the medium caused the appearance of DAAO activity. The intracellular level of DAAO induced by D-alanine depended on the medium nutrients, being highest with glucose, intermediate in the absence of glucose (independent of the presence of ammonium), and lowest in the presence of both glucose and ammonium. It should be noticed that the specific activity of about $0.6 \mathrm{U}$ (mg protein) $)^{-1}$ obtained during growth on D-alanine and glucose represents a 15 -fold increase with respect to the highest specific activity previously obtained.

To ascertain whether the effect of $\mathrm{D}$-alanine was at the level of post-translational modification or induction of enzyme synthesis, cells were grown in basal medium containing glucose and ammonium (i.e. in conditions of minimal DAAO activity) and exposed to D-alanine in the presence or absence of cycloheximide (Fig. 1). The results show that inhibition of protein synthesis completely blocked the appearance of DAAO activity, indicating that the effect of D-alanine involves de novo protein synthesis, as already reported under different growth conditions (Pilone Simonetta et al., 1982).

The results in Table 2 show that $R$. gracilis was also able to grow on succinate and malate as carbon sources, but with these nutrients the induction of DAAO by D-alanine was lower than with glucose. Addition of ammonium depressed the D-alanine-induced DAAO synthesis, but to 


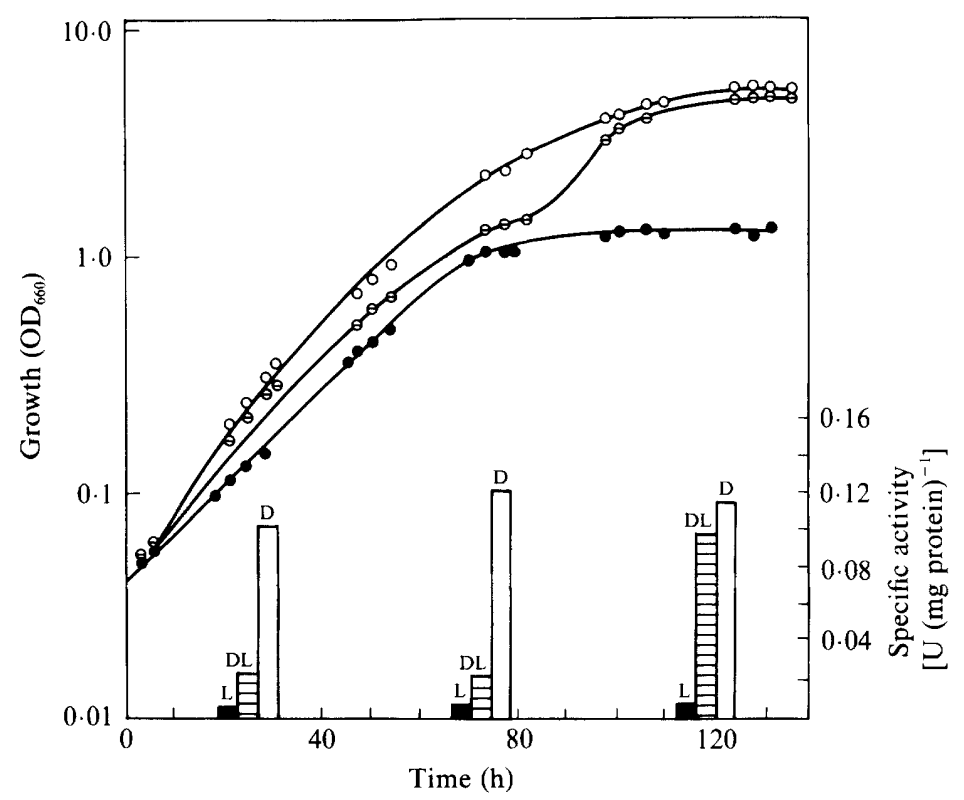

Fig. 2. Effect of D-, DL- and L-alanine on DAAO specific activity and on growth. Cells were grown on basal medium plus: $100 \mathrm{~mm}$-D-alanine $(O), 100 \mathrm{~mm}$-DL-alanine $(\ominus)$ or $100 \mathrm{~mm}$-L-alanine (๑). The histograms indicate DAAO specific activity measured at 25,75 and $120 \mathrm{~h}$.

Table 2. Effect of succinate, malate and ammonium on D-alanine-induced DAAO and on growth

Cells were grown on basal medium, supplemented with $30 \mathrm{mM}$-D-alanine plus $75 \mathrm{~mm}$-succinate or malate. $\mu$, Specific growth rate.

\begin{tabular}{|c|c|c|c|c|}
\hline \multirow{2}{*}{$\begin{array}{l}\text { Carbon } \\
\text { source }\end{array}$} & \multirow{2}{*}{$\begin{array}{l}\left(\mathrm{NH}_{4}\right)_{2} \mathrm{SO}_{4} \\
(15 \mathrm{mM})\end{array}$} & \multirow{2}{*}{$\begin{array}{c}\mu \\
\left(h^{-1}\right)\end{array}$} & \multicolumn{2}{|c|}{$\begin{array}{c}\text { DAAO specific activity } \\
{\left[\mathrm{U}(\mathrm{mg} \text { protein })^{-1}\right]}\end{array}$} \\
\hline & & & Exp. phase & Stat. phase \\
\hline Succinate & + & $0 \cdot 173$ & $0 \cdot 281$ & $0 \cdot 243$ \\
\hline Succinate & - & $0 \cdot 186$ & 0.446 & 0.462 \\
\hline Malate & + & $0 \cdot 173$ & $0 \cdot 239$ & $0 \cdot 220$ \\
\hline Malate & - & 0.193 & $0 \cdot 368$ & $0 \cdot 396$ \\
\hline
\end{tabular}

a lower extent than with glucose. Therefore, in the presence of ammonium, glucose was a better repressor of DAAO synthesis than succinate or malate.

Experiments were then performed to further investigate the ammonium effect in the presence of glucose. Cells grown to the late exponential phase in basal medium containing glucose and D-alanine (i.e. in conditions of maximal DAAO activity) were transferred to a non-growthsupporting medium containing ammonium with or without glucose, and DAAO activity was measured over $5 \mathrm{~h}$. The high initial level of enzyme activity was not diminished by the presence of either ammonium or ammonium plus glucose, and remained stable during the whole experiment (data not shown). Therefore, the lower DAAO specific activity measured in cells grown in the presence of glucose, D-alanine and ammonium with respect to cells grown in the same nutrients without ammonium cannot be ascribed to an inactivation of the enzyme.

The utilization of D- or L- or DL-alanine as a nitrogen and carbon source, and its correlation with DAAO induction, were then examined in growth experiments in the absence of glucose and ammonium (Fig. 2). In the presence of D-alanine, the specific enzyme activity was high and constant during all growth phases. The yeast was also able to grow on L-alanine, but in this case only the basal level of enzyme activity was present during all growth phases. The racemic 
Table 3. Concentrations of $D$ - and L-alanine in the external medium during growth on $D$-and DL-alanine

\begin{tabular}{|c|c|c|c|}
\hline $\begin{array}{l}\text { Carbon } \\
\text { source } \\
(100 \mathrm{~mm})\end{array}$ & $\begin{array}{l}\text { Time of } \\
\text { growth } \\
\text { (h) }\end{array}$ & $\begin{array}{l}\text { D-Alanine in } \\
\text { the medium } \\
(\mathrm{mM})\end{array}$ & $\begin{array}{l}\text { L-Alanine in } \\
\text { the medium } \\
\text { (mM) }\end{array}$ \\
\hline D-Alanine & $\begin{array}{r}24 \\
75 \\
119\end{array}$ & $\begin{array}{r}83 \cdot 0 \\
56 \cdot 0 \\
0 \cdot 4\end{array}$ & $\begin{array}{l}0 \cdot 0 \\
0 \cdot 0 \\
0 \cdot 0\end{array}$ \\
\hline DL-Alanine & $\begin{array}{r}24 \\
75 \\
119\end{array}$ & $\begin{array}{r}49 \cdot 0 \\
42 \cdot 0 \\
0 \cdot 4\end{array}$ & $\begin{array}{r}49 \cdot 0 \\
14 \cdot 0 \\
0 \cdot 0\end{array}$ \\
\hline
\end{tabular}

mixture DL-alanine could also be used as a source of both carbon and nitrogen for growth in minimal medium, but a sequential utilization of the optical isomers was evident, L-alanine being consumed first (Table 3). DAAO activity, reaching a level comparable to that obtained in the presence of D-alanine, appeared only in the stationary phase, following the depletion of the L-isomer from the medium (Fig. 2).

In all the above-mentioned conditions of DAAO induction, the same electrophoretic pattern was obtained after staining for DAAO activity (data not shown). This was similar to that previously reported (Pilone Simonetta et al., 1987a).

One of the possible explanations of the effect of L-alanine (and possibly of ammonium) on D-alanine-induced DAAO synthesis is competition with D-alanine for entry into the yeast cell. We therefore measured the initial uptake rate of labelled $\mathrm{D}$-alanine by $R$. gracilis in the presence or absence of L-alanine. The experiment was performed with cells harvested from different growth phases. To evaluate the possible induction of a specific permease, we performed uptake experiments using cells grown either in the absence or in the presence of $D$-alanine. The results shown in Fig. 3 indicate that, regardless of the presence of D-alanine in the growth medium, the uptake rate of $D$-alanine by cells in the exponential phase was high, indicating that an inducible transport system was not present. The uptake was reduced to almost zero when L-alanine was present in the assay mixture. Therefore, L- and D-alanine seem to share the same transport system. In Saccharomyces cerevisiae, similar results concerning transport of both enantiomers by the same permease have been described for methionine (Gits \& Grenson, 1967), arginine (Grenson et al., 1966) and proline (Horák \& Rihovà, 1982) (for a review on amino-acid transport in yeast, see Horák, 1986). Moreover, a clear drop in the uptake rate was observed which was parallel to the growth of the culture. In contrast, glucose uptake by the cells was the same after 8 and $16 \mathrm{~h}$ of growth (data not shown). Therefore, the decrease of uptake rate with progressing growth is not a general phenomenon in this yeast.

The specificity of the effect of L-alanine on D-alanine uptake was examined with amino acids other than L-alanine, namely the neutral amino acid L-proline and the acidic amino acid L-aspartate. Fig. 4 shows the time course of D-alanine uptake by exponentially grown cells in the presence of these amino acids and ammonium. A $97 \%$ inhibition of $1 \mathrm{mM}$-D-alanine uptake was observed with $5 \mathrm{~mm}$-L-alanine. Under the same conditions, a comparable effect $(82 \%$ inhibition) was shown by L-proline, whereas L-aspartate, as well as ammonium ( $30 \mathrm{~mm}$ ), did not significantly inhibit the uptake of $\mathrm{D}$-alanine. The results indicate that in $R$. gracilis, L-proline, but not L-aspartate, competes with D-alanine for the same carrier. A similar competition between L-alanine and L-proline has been described in S. cerevisiae (Horák \& Rihovà, 1982).

The growth-phase dependency of D-alanine uptake (Fig. 3) could explain the concurrent growth-phase dependency of DAAO synthesis induced by D-alanine in induction experiments (Fig. 5). Cells in the stationary phase showed both a more extended lag phase and a much lower rate of synthesis of DAAO than exponentially growing cells. A similar behaviour has been reported in $R$. gracilis for the induction of alcohol dehydrogenase by ethanol (Guerritore \& Hanozet, 1973). 


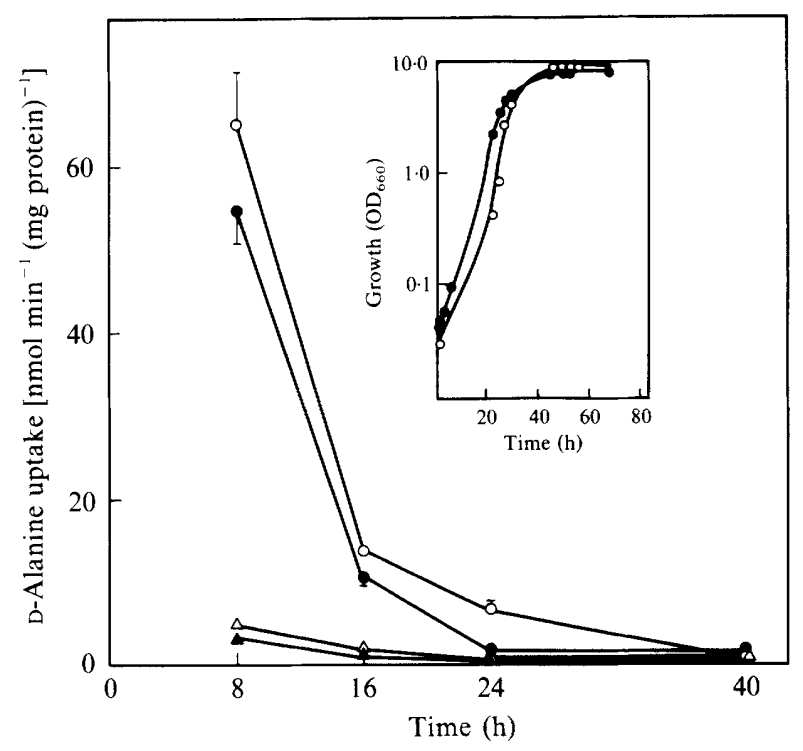

Fig. 3. Initial rate of D-alanine uptake during growth. Cells were grown for the specified times in basal medium plus glucose and the nitrogen source indicated below. The uptake of $\mathrm{D}^{-\left[{ }^{14} \mathrm{C}\right] \text { alanine was }}$ measured as described in Methods. $O$, Cells grown with $15 \mathrm{~mm}$-ammonium sulphate, uptake measured in the absence of L-alanine; - cells grown with $30 \mathrm{~mm}$-D-alanine, uptake measured in the absence of L-alanine; $\triangle$, cells grown with $15 \mathrm{mM}$-ammonium sulphate, uptake measured in the presence of $5 \mathrm{~mm}$-L-alanine; $\boldsymbol{\Delta}$, cells grown with $30 \mathrm{~mm}$-D-alanine, uptake measured in the presence of $5 \mathrm{~mm}$-L-alanine. For each condition, the initial uptake rate, expressed as nmol $\mathrm{min}^{-1}$ ( $\mathrm{mg}$ total protein $)^{-1}$, is the slope of the linear plot of $\mathrm{D}-\left[{ }^{14} \mathrm{C}\right]$ alanine uptake versus time $(0 \cdot 4,2,4 \mathrm{~min})$. The inset shows the growth curves in basal medium containing $50 \mathrm{~mm}$-glucose plus $15 \mathrm{~mm}$-ammonium sulphate (O) or 30 mM-D-alanine (๑). Error bars shown (when not smaller than symbols) represent SE.

The results reported in this paper point to two crucial aspects concerning maximal expression of DAAO in R. gracilis : (i) the inducer D-alanine must have access to the cell; (ii) it has to act at the level of enzyme synthesis. Our findings show that the first event can be prevented by the presence of L-alanine, whilst the second is controlled by the presence of both ammonium and glucose through an unidentified intracellular mechanism. Therefore the 15 -fold increase of DAAO specific activity shown by our present results, as compared to previously reported values, is due to the use of a growth medium containing D-alanine and glucose and lacking the L-isomer and ammonium.

Some comment is appropriate concerning our previous report (Pilone Simonetta et al., 1982). Both the appearance of DAAO at the onset of the stationary phase of growth in an organic medium containing DL-alanine, and the low specific enzyme activity attained, can be ascribed to the presence in the medium, during the exponential phase, of $L$-alanine plus other L-amino acids produced from the organic nitrogen source (acting at the level of inducer exclusion) and to the combined presence of glucose and ammonium (acting at the level of enzyme expression). All these nutrients, except $\mathrm{D}$-alanine, are possibly exhausted at the beginning of the stationary phase of growth, but at the same time the inducibility of the enzyme markedly decreases (see Fig. 5).

Some aspects of the mechanism of regulation of DAAO synthesis in $R$. gracilis are similar to those in other micro-organisms, namely $N$. crassa (Sikora \& Marzluf, 1982), C. utilis (Zwart et al., 1983) and T. variabilis (Kubicek-Pranz \& Röhr, 1985a). In all these species and in R.gracilis the enzyme is induced by D-amino acids, and the presence of ammonium in the culture medium has little or no effect on the activity of the enzyme. In contrast, the regulation of DAAO synthesis by glucose and ammonium is different: in C. utilis and $N$. crassa a glucose repression is present, while in $T$. variabilis the induced enzyme level is completely independent of the presence of glucose, with or without ammonium. In $R$. gracilis glucose per se is not a repressor and only the 


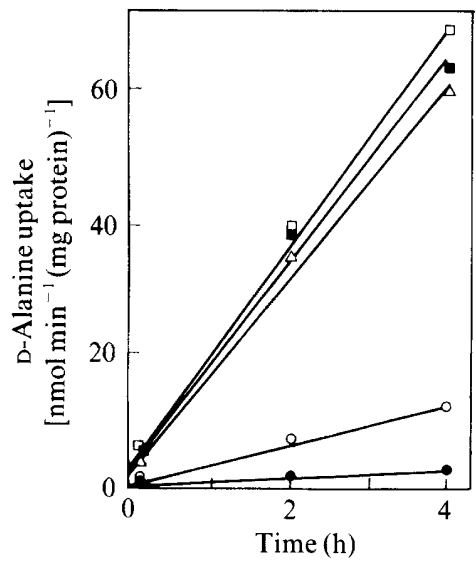

Fig. 4

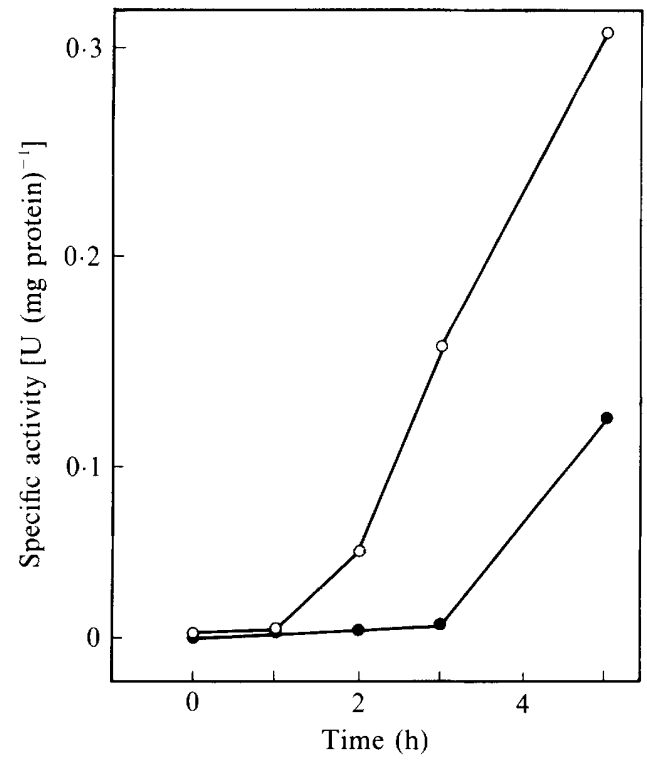

Fig. 5

Fig. 4. Effect of amino acids and ammonium on the initial uptake of D-alanine. Cells were grown to the exponential phase in basal medium containing $50 \mathrm{~mm}$-glucose plus $15 \mathrm{~mm}$-ammonium sulphate. The uptake of $1 \mathrm{~mm}-\mathrm{D}-\left[{ }^{14} \mathrm{C}\right]$ alanine was measured in the absence $(\square)$ or in the presence of $15 \mathrm{~mm}$ ammonium sulphate $(\boldsymbol{\square}), 5 \mathrm{~mm}$-L-aspartate $(\triangle), 5 \mathrm{mM}$-L-proline $(O)$ or $5 \mathrm{mM}$-L-alanine $(\bullet)$.

Fig. 5. Induction of DAAO by D-alanine in different growth phases. Cells were grown for $8 \mathrm{~h}(\mathrm{O})$ or $40 \mathrm{~h}()_{)}$in basal medium containing $50 \mathrm{~mm}$-glucose plus $15 \mathrm{~mm}$-ammonium sulphate, harvested, washed and suspended in basal medium containing $50 \mathrm{~mm}$-glucose plus $30 \mathrm{~mm}$-D-alanine. DAAO specific activity was measured at the times specified after the addition of D-alanine.

combined effect of glucose and ammonium acts as an intracellular signal for preventing enzyme induction. Moreover, at variance with all the other reports, maximal expression of DAAO in $R$. gracilis is obtained when $\mathrm{D}$-alanine is present as the sole nitrogen source together with glucose as the carbon source.

This work was supported by grants from Ministero della Pubblica Istruzione, Rome.

\section{REFERENCES}

Brigth, H. J. \& Porter, D. J. T. (1975). Flavoprotein oxidases. In The Enzymes, vol. XII, pp. 421-505. Edited by P. D. Boyer. New York: Academic Press.

BURKHARD KRESZE, G. (1983). Methods for protein determination. In Methods of Enzymatic Analysis, vol. II, pp. 84-95. Edited by H. U. Bergmeyer. Weinheim: Verlag Chemie.

Davis, B. J. (1964). Disc electrophoresis. II. Method and application to human serum proteins. Annals of the New York Academy of Sciences 121, 404-427.

Funayama, S., Gancedo, J. M. \& Gancedo, C. (1980). Turnover of yeast fructose bisphosphatase in different metabolic conditions. European Journal of Biochemistry 109, 61-66.

Gits, J. J. \& Grenson, M. (1967). Multiplicity of the amino acid permease in Saccharomyces cerevisiae. Evidence for a specific methionine-transporting system. Biochimica et biophysica acta 135, 507-516.
Grassl, M. \& SuPP, M. (1983a). D-Alanine. In Methods of Enzymatic Analysis, vol. VIII, pp. 336340. Edited by H. U. Bergmeyer. Weinheim: Verlag Chemie.

GrassL, M. \& SuPP, M. (1983b). L-Alanine. Determination with alanine aminotransferase and lactate dehydrogenase. In Methods of Enzymatic Analysis, vol. VIII, pp. 345-349. Edited by H. U. Bergmeyer. Weinheim: Verlag Chemie.

Grenson, M., Mousset, M., Wiame, J. M. \& Bechet, J. (1966). Multiplicity of the amino acid permeases in Saccharomyces cerevisiae. I. Evidence for a specific arginine-transporting system. Biochimica et biophysica acta 127, 325-338.

Guerritore, A. \& Hanozet, G. M. (1973). Control of alcohol dehydrogenase level in the yeast Rhodotorula gracilis. Italian Journal of Biochemistry 22, 244257. 
Hamilton, G. A. (1985). Peroxisomal oxidases and suggestion for the mechanisms of action of insulin and other hormones. Advances in Enzymology 57, 85-178.

Horák, J. (1986). Amino acid transport in eukaryotic microorganisms. Biochimica et biophysica acta 864, 223-256.

HoRák, J. \& Ř́́nOvá, L. (1982). L-Proline transport in Saccharomyces cerevisiae. Biochimica et biophysica acta 691, 144-150.

KUbiCEK-PRANZ, E. M. \& RöHR, M. (1985a). Formation of D-amino-acid oxidase in the yeast Trigonopsis variabilis. Canadian Journal of Microbiology 31, 625628.

Kubicek-Pranz, E. M. \& Röhr, M. (1985b). D-Amino-acid oxidase from the yeast Trigonopsis variabilis. Journal of Applied Biochemistry 7, 104-113.

Massey, V. \& Hemmerich, P. (1980). Active-site probes of flavoproteins. Biochemical Society Transactions 8, 246-256.

Pilone Simonetta, M., Vanoni, M. A. \& Curti, B.
(1982). D-Amino-acid oxidase activity in the yeast Rhodotorula gracilis. FEMS Microbiology Letters 15, 27-31.

Pilone Simonetta, M., Vanoni, M. A. \& Casalin, P. (1987a). Purification and properties of D-amino-acid oxidase, an inducible flavoenzyme from Rhodotorula gracilis. Biochimica et biophysica acta 914, 136-142. Pilone Simonetta, M., Casalin, P., Pollegioni, L., VANONI, M. A. \& CURTI, B. (1987b). D-Amino-acid oxidase from Rhodotorula gracilis. In Flavins and Flavoproteins, pp. 205-208. Edited by D. E. Edmondson \& D. B. McCormick. Berlin \& New York: Walter de Gruyter.

Sikora, L. \& Marzluf, G. A. (1982). Regulation of L-amino-acid oxidase and D-amino-acid oxidase in Neurospora crassa. Molecular and General Genetics 186, 33-39.

Zwart, K. B., Overmars, E. H. \& HARder, W. (1983). The role of peroxisomes in the metabolism of D-alanine in the yeast Candida utilis. FEMS Microbiology Letters 19, 225-231. 